\title{
IN MEMORIAM: PHILIP BROMBERG
}

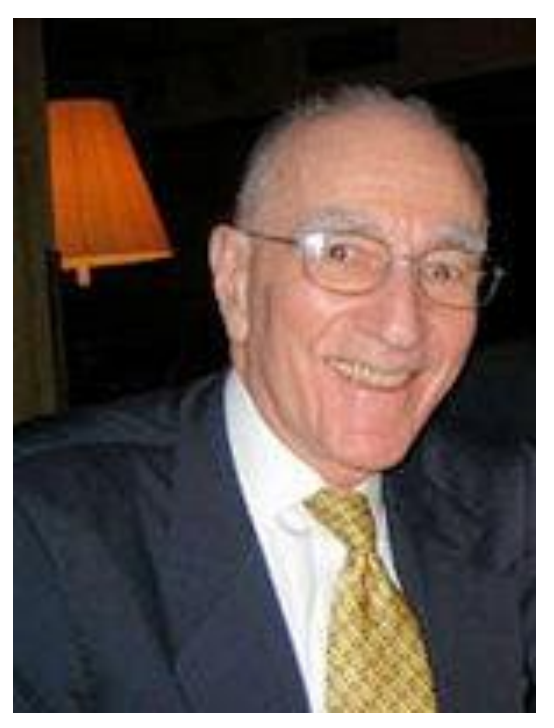

\section{Realizado por Sandra Buechler ${ }^{1}$}

Philip Bromberg, Ph.D. murió por causas naturales el 18 de mayo de 2020. El mundo perdió a un analista, supervisor, profesor, mentor, colega y amigo aclamado internacionalmente. Philip era un miembro apreciado del cuerpo docente del Instituto William Alanson White, del Programa Postdoctoral de la NYU en Psicoterapia y Psicoanálisis, y del Centro Stephen Mitchell de Estudios Relacionales,y miembro fundador de la Asociación Internacional para el Psicoanálisis Relacional y la Psicoterapia, así como editor emérito de la revista Contemporary Psychoanalysis, y miembro de los consejos editoriales de Psychoanalytic Dialogues, del Journal of the American Academy of Psychoanalysis y de Psychoanalytic Inquiry. Fue autor de numerosas publicaciones, entre ellas Standing in the Spaces: Essays on Clinical Process, Trauma, and Dissociation ; (Analytic Press, 1998); Awakening the Dreamer: Clinical Journeys (Analytic Press, 2006); y La sombra del tsunami y el desarrollo de la mente relacional (Routledge, 2011; Ágora Relacional, 2019). El Dr. Bromberg también fue miembro de la Asociación Americana de Psicología y del Diplomado ABPP en Psicología Clínica. Esta es sólo una pequeña muestra de sus afiliaciones y logros.

${ }^{1}$ Buechler, S. (2020). In Memoriam: Philip Bromberg. Clínica e Investigación Relacional, 14 (2): 546549. [ISSN 1988-2939] [Recuperado de www.ceir.info] DOI: 10.21110/19882939.2020.140226 
Cuando Philip murió, analistas de todo el mundo expresaron dolor con un grado muy inusual de intensidad a corazón abierto. Philip era extraordinario. Tuvo un inmenso impacto en generaciones de analistas, a través de su enseñanza, mentoría, amistades y publicaciones ampliamente leídas. El uso poético del lenguaje y la profunda visión de Philip son legendarios. He tocado la vida de innumerables clínicos y de sus pacientes a través de sus escritos sobre los temas de disociación normal y patológica, trauma, la multiplicidad del Self, la relación de tratamiento, la relación de supervisión, y muchos otros temas. Philip no era sólo prolífico, reflexivo e inteligente. Era ingenioso y sabio.

Hacia los colegas, Philip podría ser juguetón, extremadamente generoso y enormemente solidario, sobre todo para aquellos que estaban tratando de abrir nuevos caminos, tanto clínica como teóricamente. Muchos Iloran la pérdida de su vida, de su punto de vista único y calidez inconfundible. Su propio trabajo innovador proporcionó una base para el desarrollo de incontables colaboraciones innovadoras en la práctica analítica y en su literatura.

Trabajé por primera vez con Philip, como mi maestro y supervisor, en 1980, cuando era candidato de segundo año en el Instituto William Alanson White, en la ciudad de Nueva York. Tuvo una enorme influencia en mi pensamiento, en mi desarrollo como clínico y, sobre todo, en mi desarrollo como ser humano. Su voz, su sonrisa, y el brillo en sus ojos, estaban llenos de vida. La fuerza vital en Philip era contagiosa. No sé cómo alguien podría estar cerca de él sin sentir su carisma.

Philip impartió un curso que era obligatorio, sobre proceso clínico, en el Instituto W.A. White. Su clase fue una experiencia inolvidable. Cada candidato presentó una grabación en cinta de una sesión. Me impresionó mucho lo rápido que Philip atrapó lo esencial mientras escuchaba. De alguna manera, sólo le tomó minutos entender el dilema del paciente y los dilemas del clínico neófito. Para mí, la clase reforzó mis esperanzas como analista. Vi lo que era posible. Sabía que estaba muy lejos de lograr algo como su perspicacia. Pero también intuí que un clínico que se acercase algo a ese nivel podría cambiar muchas vidas. En retrospectiva, creo que esa clase ayudó a cimentar mi propia determinación de convertirme en el mejor clínico que pude.

Así que, por supuesto, me convertí en su supervisada. Siempre me ha sido difícil capturar, con palabras, exactamente cómo creo que funciona la supervisión. Lo he intentado muchas veces en el pasado (2008, 2009, 2012, 2017, 2019). Al igual que el psicoanálisis en sí, hay algo inefable en ello. He llegado a creer que, en su mejor momento, los supervisores dejan claro su propio pensamiento clínico dando voz a sus pensamientos, como ellos piensan. He tenido la mejor supervisión cuando el supervisor se sintió libre de pensar en expresa. Este material es para uso científico y profesional exclusivamente y puede contener información clínica sensible. Los editores no se responsabilizan de los contenidos de los autores. Dirigir las consultas sobre derechos y autorizaciones a ceir@psicoterapiarelacional.es 
voz alta, ya que escucharon sobre el proceso entre mí y mi paciente. En ese sentido, Philip era, con toda claridad, un maestro. Mi propia frase para los mentores que pueblan mi mente es que están en mi "coro interno". Philip es un miembro permanente del coro.

Otra cualidad que creo que es esencial para la supervisión analítica es la integridad del supervisor. El supervisado debe creer que el supervisor siente lo que dice, y dice lo que siente. A veces eso requiere valor, por parte de ambos participantes. Pero la integridad es tan necesaria para la supervisión como para el tratamiento. En ambos procesos, la verdad tiene que importar. Philip tenía ese respeto por la verdad más que cualquier otro que haya conocido. Lo que le hizo un excelente supervisor es que incluso cuando era franco sobre el tipo de desarrollo que pensaba que yo necesitaba, o lo que pensó que debía cambiar, siempre supe que venía del corazón. Realmente se preocupaba por mi desarrollo. Eso me hizo posible oír lo que tenía que decir.

Esto no quiere decir que fuera un supervisor fácil, o que su docencia fuese una brisa suave. En absoluto. De hecho, la mayoría de nosotros nos acercábamos a la clase de Philip con cierto temor. Todavía estaba en sus inicios nuestra formación, y tuvimos que exponer nuestro trabajo los unos a los otros, y a Philip, un miembro senior del cuerpo docente. Lo que también sabíamos, a través de la vivencia, era que valía la pena. Innumerables candidatos y graduados antes y después de nosotros dan fe de los beneficios de estar en la clase de Philip.

Mirándolo 40 años más tarde, me imagino que yo no era un supervisada fácil para Philip, ni que él fuera un supervisor o maestro fácil. Llegué a él con material clínico extremadamente complicado. Un paciente cuyo tratamiento supervisaba se suicidó. Otro tenía una vida tremendamente gravada por comportamientos compulsivos y rituales. Cuando llegué a la supervisión, yo era un clínico más experimentado que la mayoría de los candidatos, habiendo tenido más de una década de experiencia clínica en entornos hospitalarios y clínicos, con niños y adultos. También había hecho varios años de supervisión de trabajadores de salud mental y psicólogos en prácticas. Creo que tenía algunas de las fortalezas de un buen supervisado, que estaba muy dedicada al trabajo, y realmente quería aprender. Pero también era testaruda, cabezota, con muchas opiniones y ferozmente decidida a hacer lo que creía correcto clínicamente.

Si me conoces, puedes imaginar que siempre fui externamente respetuosa con mis supervisores. Pero eso no significaba que siempre estuviera realmente abierta a su opinión. A Philip no le llevó mucho tiempo reconocer esto. Y no le llevó mucho tiempo comentarlo. Pero su talento estaba en decir lo que vio sobre mí de una manera que me hizo sentir entendida y no avergonzada. Siempre me quedó claro que quería ayudarme a 
crecer. Mientras Philip tomaba muy en serio las dificultades de los tratamientos que estaba realizando, al mismo tiempo que me comunicaba su confianza en mí. Y siempre tenía un brillo en los ojos, y un calor en su rostro, que me decía que todo estaría bien al final. Así fue.

Ya sea en la supervisión, en clase, en un coloquio, en un ambiente político cargado, o en un intercambio personal, la voz de Philip era reconocible. Era directo, directo y a menudo apasionado por aportar su visión. Cada vez que hablaba en las reuniones, o leía trabajos, su voz era singular. También siempre venía preparado. Algunas personas de la tercera edad se aflojan, leyendo los mismos papeles una y otra vez, y se ponen perezosos hacia el final de sus carreras. No fue así con Philip. Creo que fue una marca de su respeto por su audiencia, y, en cierto sentido, por sí mismo, por lo que no hizo eso. Y claramente le encantaba exponer nuevas ideas y ponerlas a prueba ante una audiencia. Tenía la curiosidad de un explorador, siempre listo para la próxima aventura intelectual.

No es de extrañar que lo eche de menos. De hecho, ya lo hago. Pero como dije en el intercambio de correos de nuestro instituto cuando oí por primera vez sobre su muerte, tengo a mi propio Philip interiorizado, y él siempre me enseñará.

\section{Referencias}

Bromberg, P. M. (1998). Standing in the Spaces: Essays on Clinical Process, Trauma, and Dissociation (Hillsdale, N.J.: Analytic Press).

Bromberg, P. M. (2006). Awakening the Dreamer: Clinical Journeys (Hillsdale, N.J.: Analytic Press).

Bromberg, P. M. (2019). La sombra del tsunami y el desarrollo de la mente relacional. Madrid: Ágora Relacional (Original: Nueva York: Routledge, 2011.

Buechler, S. (2014). Marcando una diferencia en la vida de los pacientes. Madrid: Ágora Relacional (Original: Nueva York: Routledge, 2008).

Buechler, S. (2009). (Ed.). (Ed.). Special issue on the ideal psychoanalytic institute. Contemporary Psychoanalysis, 45 .

Buechler, S. (2012). Still Practicing: The Heartaches and Joys of a Clinical Career. (New York: Routledge).

Buechler, S. (2017). Psychoanalytic Reflections: Training and Practice. (New York: IPBooks).

Buechler, S. (2019). Psychoanalytic Approaches to Problems in Living (New York: Routledge). 